\title{
RANCANG DAN BANGUN SISTEM INFORMASI \\ ADMINISTRASI DIKLAT PADA PT PLN (PERSERO) WILAYAH SULSELRABAR BERBASIS WEB
}

\author{
Farida Yusuf* \\ *Jurusan Sistem Informasi Fakultas Sains dan Teknologi \\ Universitas Islam Negeri (UIN) Alauddin Makassar \\ email: faridayusuf19@gmail.com
}

\begin{abstract}
Abstrak: Pendidikan dan Pelatihan atau biasa disebut dengan Diklat, dapat diartikan sebagai akuisisi dari pengetahuan (knowledge), keterampilan (skills), dan sikap (attitudes) yang memampukan manusia untuk mencapai tujuan individual dan organisasi saat ini dan masa depan. Salah satu perusaahan yang melakukan diklat adalah PT. PLN (Persero) Wilayah SULSELRABAR. PT PLN (Persero) Wilayah SULSELRABAR dalam pelaksanaan proses monitoring diklat mulai dari pengusulan, pengakomodasian diklat, sertifikasi diklat, persetujuan, hingga proses input hasil pelaksanaan sertifikasi dilakukan tanpa menggunakan sistem atau aplikasi. Dalam pelaksanaannya proses monitoring dilakukan oleh lebih dari satu pegawai dengan pembagian tugas yang berbeda menggunakan aplikasi excel sebagai media pengelolahan data. Penelitian ini bertujuan untuk merancang dan membangun sistem informasi administrasi diklat berbasis Web pada PT. PLN (Persero) Wilayah SULSELRABAR yang dapat mengatasi masalah tentang sulitnya mendapatkan data dan informasi terkait dengan diklat dikarenakan perusahaan memiliki banyak data yang harus diolah. Metodologi penelitian yang digunakan terdiri dari metode pengembangan sistem yaitu SDLC (System Development Life Cycle)waterfall. Sedangkan perkakas yang digunakan adalah PHP, HTML, JavaScript, CSS, Jquery, MySQL, mpdf, dan Xampp. Hasil dari penelitian ini adalah rancangan dan sistem informasi administrasi diklat berbasis web. Penelitian ini menyimpulkan sistem yang dibangun dapat pengelolahan data dan penyajian informasi tentang admnisitrasi diklat dengan efektif dan efesien.
\end{abstract}

Kata Kunci: Administrasi Diklat, Sistem Informasi, SDLC Waterfall, PHP, HTML, JavaScript, CSS, Jquery, MySQL, mpdf, Xampp. 


\section{PENDAHULUAN}

endidikan dan Pelatihan atau biasa disebut dengan Diklat, dapat
diartikan sebagai akuisisi dari pengetahuan (knowledge), keterampilan
(skills), dan sikap (attitudes) yang memampukan manusia untuk mencapai tujuan individual dan organisasi saat ini dan masa depan. Diklat sebagai upaya dalam mengembangkan sumber daya manusia (SDM) terutama untuk mengembangkan kemampuan intelektual dan kepribadian manusia. Salah satu perusahaan yang melakukan kegiatan diklat adalah PT PLN (Persero). Perusahaan ini merupakan perusahaan BUMN (Badan Usaha Milik Negara) yang menangani tentang kelistrikan di Indonesia. Kegiatan diklat ini dilaksanakan di Pusat Pendidikan dan Latihan (Pusdiklat) milik PLN (Persero). Pada perusahaan PT PLN (Persero) mengharuskan pegawainya khususnya pada bidang bisnis inti untuk mengikuti sertifikasi kompetensi sesuai dengan undang-undang No. UU 30 tahun 2009 tetntang Ketenagalistrikan Pasal 44 ayat (6) yaitu "Tenaga teknik yang bekerja dibidang ketenagalistrikan wajib memiliki sertifikasi kompetensi”. Saat ini, PT PLN (Persero) Wilayah SULSELRABAR dalam pelaksanaan proses monitoring diklat mulai dari pengusulan, pengakomodasian diklat, sertifikasi diklat, persetujuan, hingga proses input hasil pelaksanaan sertifikasi dilakukan tanpa menggunakan sistem atau aplikasi. Dalam pelaksanaannya proses monitoring dilakukan oleh lebih dari satu pegawai dengan pembagian tugas yang berbeda menggunakan aplikasi excel sebagai media pengelolahan data. Hal ini tentu kurang efektif dan efisien karena file penyimpanan data dilakukan secara terpisah-pisah dan menyebabkan data menjadi tidak akurat. Data yang terpisahpisah menyebabkan data tersebut tidak aman dari kecelakaan atau penyalahgunaan data.

Berdasarkan uraian di atas, dapat dirancang sebuah sistem informasi administrasi diklat yang berbasis Web sebagai solusi yang tepat dari permasalahan tersebut. Penulisan judul penelitian ini "Rancang dan Bangun Sistem Informasi Administrasi Diklat pada PT. PLN (Persero) Wilayah SULSELRABAR Berbasis Web “. 


\section{METODELOGI PENELITIAN}

\section{Pendekatan Penelitian}

Penelitian ini menggunakan pendekatan penelitian saintifik yaitu pendekatan berdasarkan wawancara, ilmu pengetahuan dan teknologi.

\section{Sumber Data}

Menurut Suharsimi Arikunto (2010:265), instrumen pengumpulan data adalah alat bantu yang dipilih dan digunakan oleh peneliti dalam kegiatannya mengumpulkan data agar kegiatan tersebut menjadi sistematis dan dipermudah olehnya. Dan sumber data penilitian ini terbagi atas dua:

a. Sumber data primer

Data primer adalah data yang bersumber dari hasil penilitian lapangan (field research) yang diperoleh melalui metode wawancara mendalam, observasi dan dokumentasi.

b. Sumber data sekunder

Data sekunder adalah data tertulis hasil kajian pustaka yang bertujuan memperoleh teori yang relevan baik yang bersumber dari karya ilmiah, referensi buku, jurnal ilmiah, dan bahan dokumentasi lainya serta data tertulis yang relevan dengan orientasi penelitian.

\section{Metode Pengumpulan Data}

Metode pengumpulan data yang digunakan adalah metode Kuantitatif. Sugiyono (2012:7) metode kuantitaif yaitu metode tradisional, karena metode ini sudah cukup lama digunakan sehingga sudah mentradisi sebagai metode untuk penelitian.

Menurut Sugiyono(2012:137) berdasarkan teknik pengumpulan data penelitian kuantitatif dapat dilakukan dengan cara:

a. Observasi

Metode observasi merupakan salah satu cara yang bisa digunakan untuk mengumpulkan data. Metode observasi ini biasanya digunakan untuk meneliti objek penelitian secara langsung dan 
mengetahui perilaku masyarakat secara detail.

b. Wawancara

Wawancara yaitu tanya jawab peneliti dengan narasumber. Wawancara adalah percakapan dengan maksud tertentu, percakapan itu dilakukan oleh dua pihak, yaitu pewawancara (interview) yang mengajukan pertanyaan dan terwawancara yang memberikan jawaban atas pertanyaan itu.

c. Studi Pustaka

Studi Pustaka adalah motode pengumpulan data yang bersumber dari buku referensi, jurnal, paper, website dan bacaan-bacaan yang ada kaitannya dengan judul penelitian yang dapat menunjang pemecahan permasalahan yang didapatkan dalam penelitian.

\section{HASIL DAN PEMBAHASAN}

\section{Analisis Sistem yang Sedang Berjalan}

Dalam perancangan aplikasi ini, perlu adanya Analisis sistem yang berjalan yang berlaku dengan mempelajari suatu permasalahan yang terjadi pada objek penelitian. Berikut gambaran bagan alur sistem yang berjalan pada PT PLN (Persero) Wilayah SULSELRABAR: 


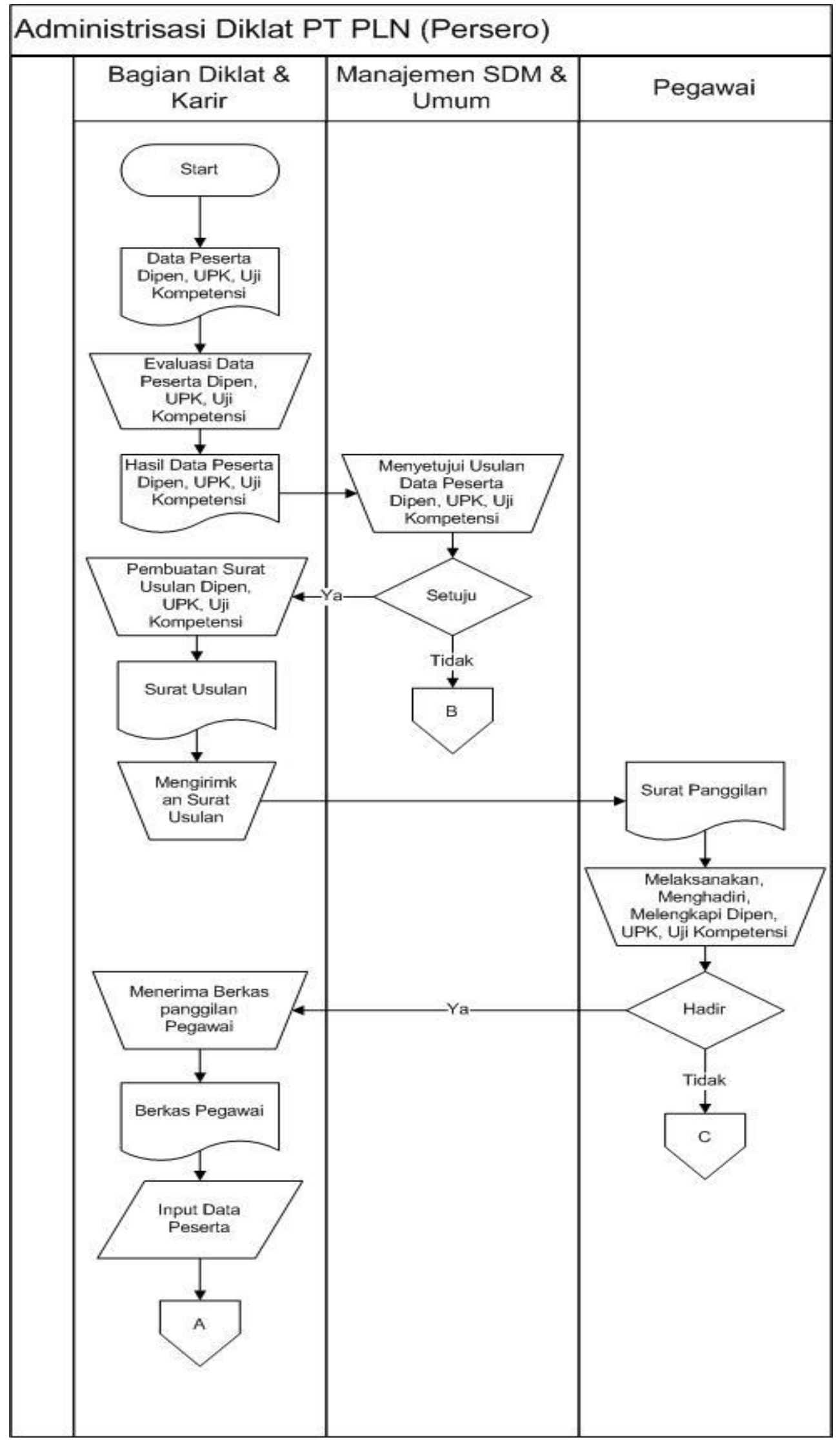


Farida Yusuf, Rancang dan Bangun Sistem Informasi Administrasi Diklat pada PT PLN ..._ 215

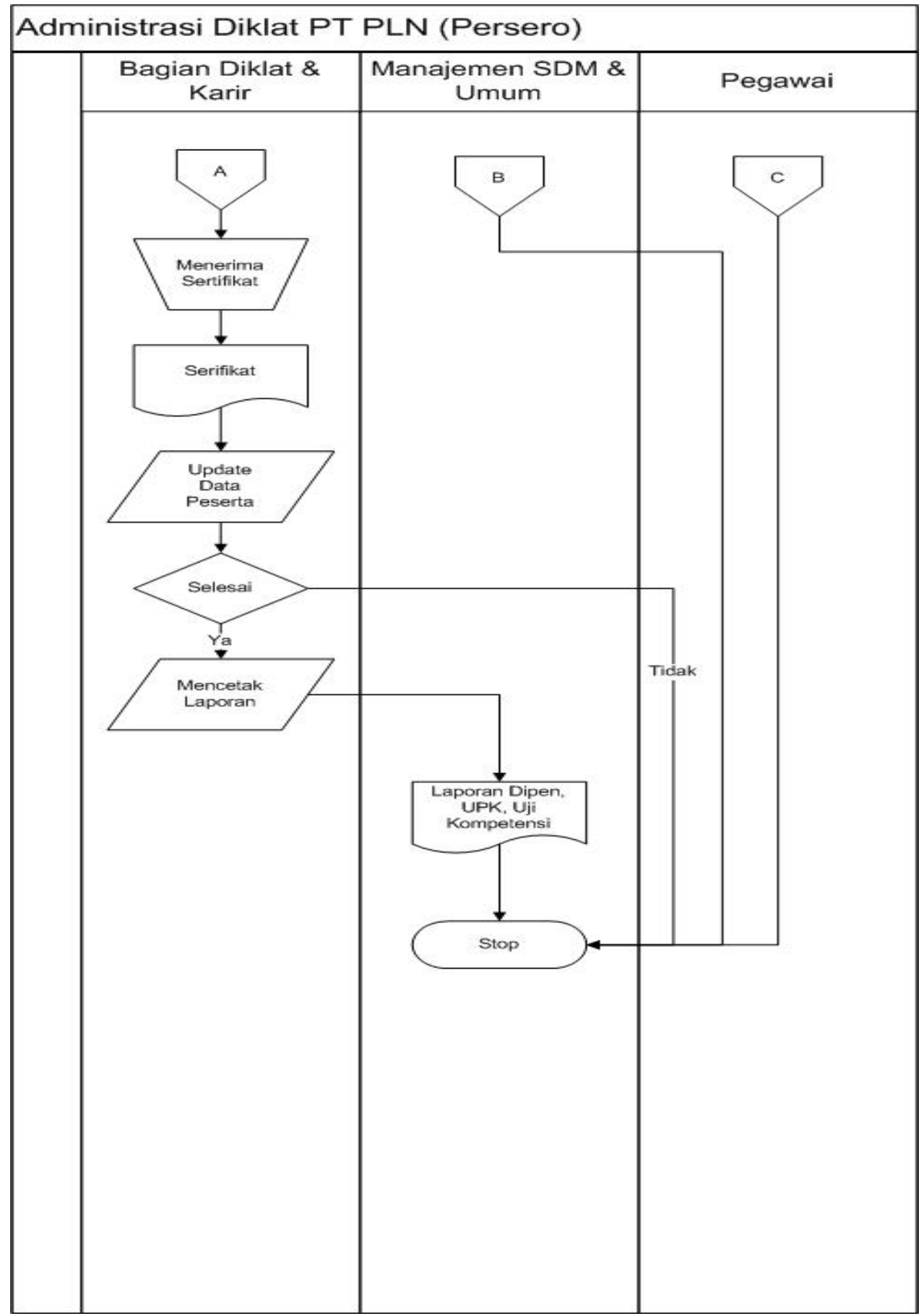

\section{Perancangan Sistem yang Diusulkan}

Berdasarkan bagan alur sistem yang berjalan, maka dapat dilakukan pengembangan sistem dengan membangun sebuah Web Publikasi Perencanaan Dan Realisasi Anggaran untuk memudahkan dan bentuk transparansi secara universal dalam penyajian informasi mengenai Desa Kabubu, sehingga perlu disimpulkan rancangan sistem yang diusulkan. 


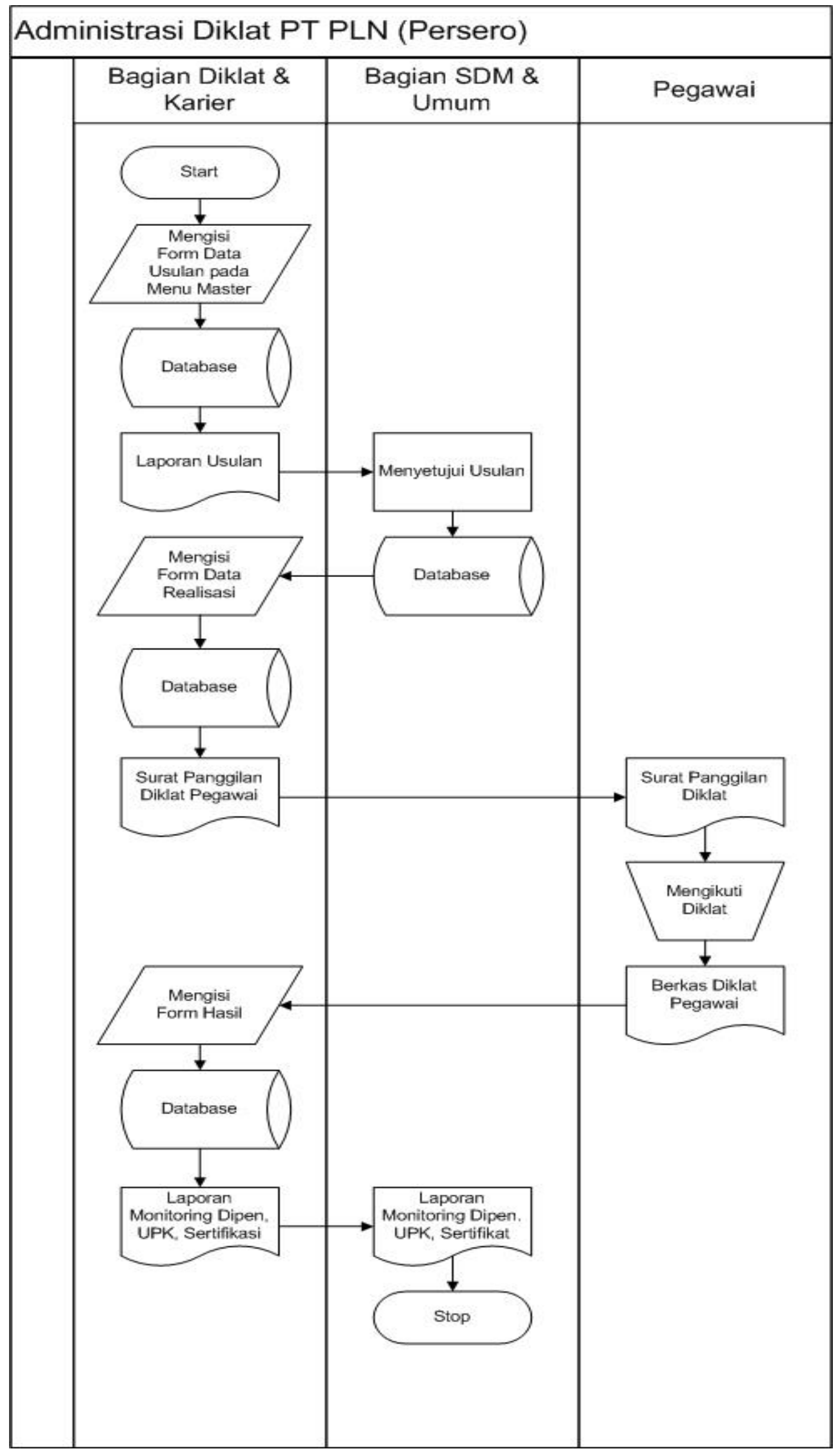




\section{a. Analisis Masalah}

Sistem informasi administrasi diklat pada PT PLN (Persero) Wilayah SULSELRABAR merupakan sistem informasi yang dapat menyiapkan penyimpanan data-data seluruh nama pegawai yang telah mengusulkan namanya pada aplikasi yang harus diisi dari Pusdiklat. Nama-nama yang telah diusulkan akan diproses oleh penanggung jawab Diklat di PT PLN (Persero). Selain itu, sistem informasi ini juga dapat menyajikan laporanlaporan yang dibutuhkan oleh Bagian Diklat \& Karier untuk diserahkan kepada Manajer Bagian SDM \& Umum.

Pada uraian analisis sistem yang sedang berjalan, terdapat tahapan pegawai bidang diklat \& karier mengumpulkan data dan berkas para pegawai yang ingin mengukuti diklat. Tahapan pengumpulan tersebut memakan waktu yang lama karena PLN memiliki banyak pegawai yang harus mengikuti diklat yang telah ditentukan dan yang ingin diikuti oleh pegawai. Ini juga menyebabkan tidak terintegrasinya data-data pegawai yang hanya dalam bentuk berkas. Sehingga menyebabkan tahap pembuatan laporan di akhir mengenai diklat juga memakan waktu yang lama. Adanya sistem informasi ini dapat menjadi solusi yang tepat dari permasalahan tersebut. Sistem informasi ini dapat membantu pegawai bidang diklat \& karier, dan manajer SDM dalam menjalankan tugas-tugasnya secara efektif dan efisien dalam kegiatan yang berkaitan dengan pelaksanaan diklat.

\section{b. Analisis Kebutuhan Sistem}

\section{1) Kebutuhan Antar Muka (Interface)}

Kebutuhan-kebutuhan antar muka untk membangun aplikasi ini yaitu sebagai berikut :

a) Sistem informasi yang dibangun akan mempunyai antarmuka yang familiar dan mudah digunakan bagi pengguna. 
b) Sistem informasi ini memungkinkan admin melakukan pembatasan akses pada user yang terdapat pada menu pengaturan user.

c) Sistem informasi ini memiliki menu master data yang terdiri dari data peserta diklat penjenjangan, uji portofolio kompetensi, uji kompetensi, unit, berita acara, laporan.

d) Sistem informasi ini menyajikan laporan-laporan yang berkaitan dengan diklat yaitu : laporan diklat penjenjangan, laporan uji portofolio kompetensi, laporan sertifikasi.

e) Sistem informasi ini juga memungkinkan user mengubah password akunnya.

f) Sistem informasi ini memiliki tampilan tanggal dan jam.

\section{2) Kebutuhan Data}

Data yang diolah aplikasi ini yaitu sebagai berikut :

a) diklat penjenjangan,

b) uji portofolio kompetensi,

c) uji kompetensi,

d) unit,

e) berkas berita acara UPK,

f) laporan-laporan

\section{3) Kebutuhan Fungsional}

Kebutuhan fungsional merupakan penjelasan proses fungsi yang berupa penjelasan secara terinci setiap fungsi yang digunakan untuk menyelesaikan masalah.

Fungsi-fungsi yang dimiliki oleh aplikasi adalah sebagai berikut :

a) Menampilkan dan mengelolah data-data dan file-file mengenai berbagai macam diklat.

b) Dapat mencetak dan men-download laporan-laporan dan data-data mengenai diklat. 
c) Dapat mengunggah file-file mengenai administrasi diklat seperti file sertifikat, berita acara upk, dan lain-lain.

\section{c. Analisis Kelemahan Sistem}

Sistem informasi administrasi diklat pada PT. PLN Wilayah SULSELRABAR merupakan sistem informasi yang berbasis web yang dapat menyajikan data-data dan mengelolah data-data tersebut menjadi laporan-laporan yang berkaitan dengan diklat. Pada sistem informasi ini kemungkinan kecepatan melayani user lambat dikarenakan data yang begitu besar yang ditampung oleh sistem informasi ini.

\section{Perancangan Sistem}

Perancangan sistem menggunakan DFD (Data Flow Diagram) dimulai dari Diagram Konteks (Level 0), Diagram Berjenjang, Diagram Level 1, dan Diagram Level 2.

\section{a. Diagram Konteks (level 0)}

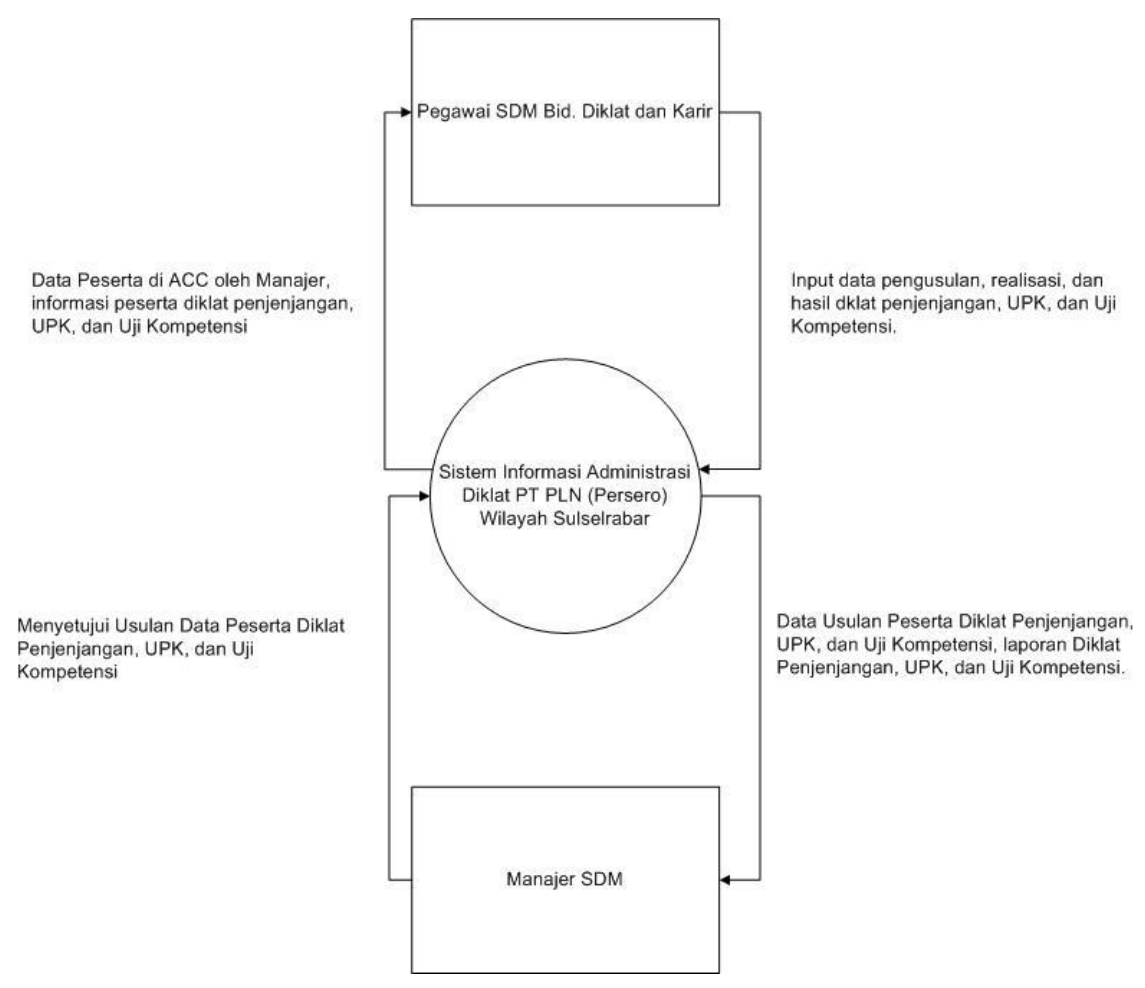


b. Diagram Berjenjang

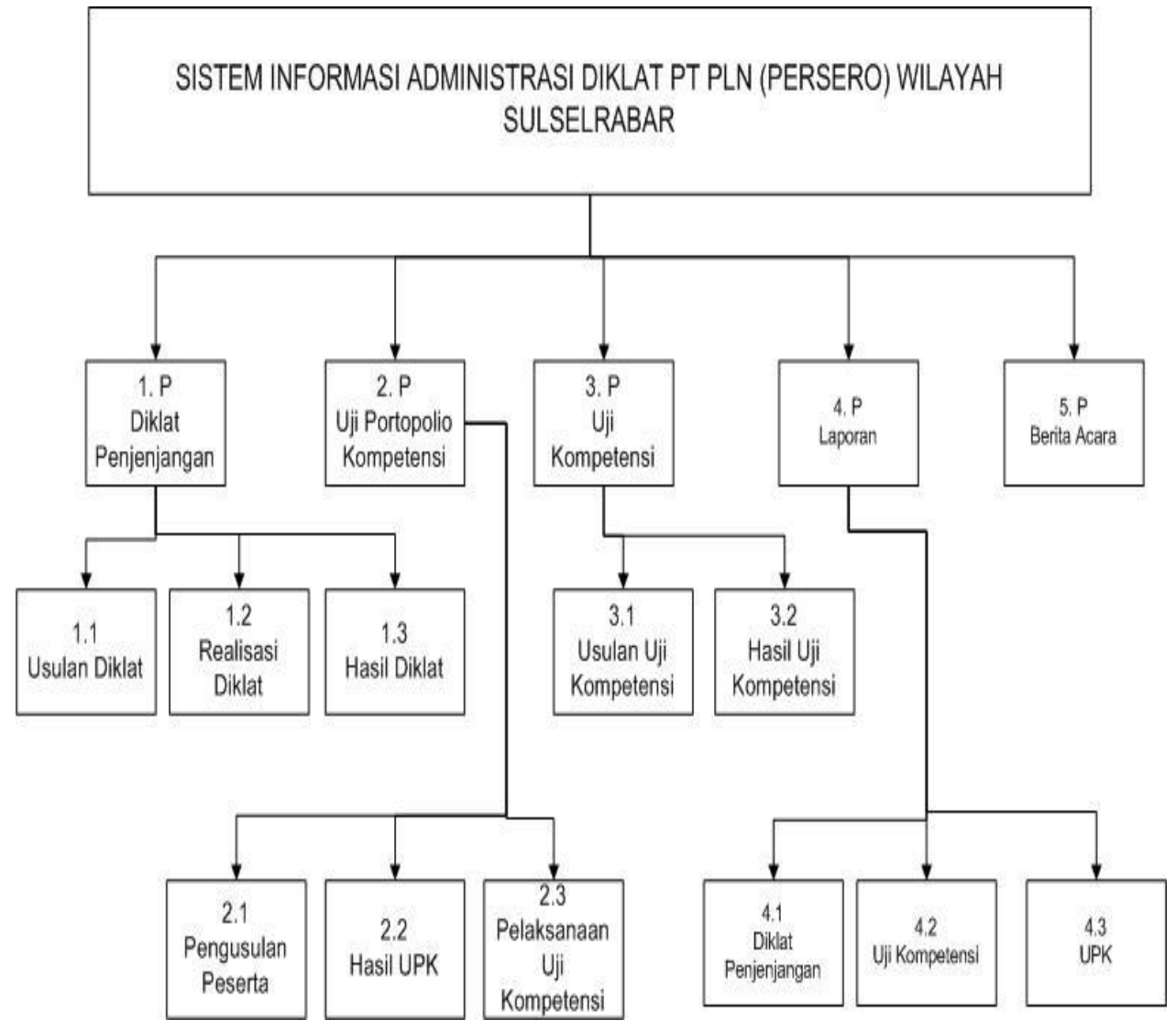


Farida Yusuf, Rancang dan Bangun Sistem Informasi Administrasi Diklat pada PT PLN ..._ 221

\section{c. Diagram Level 1}

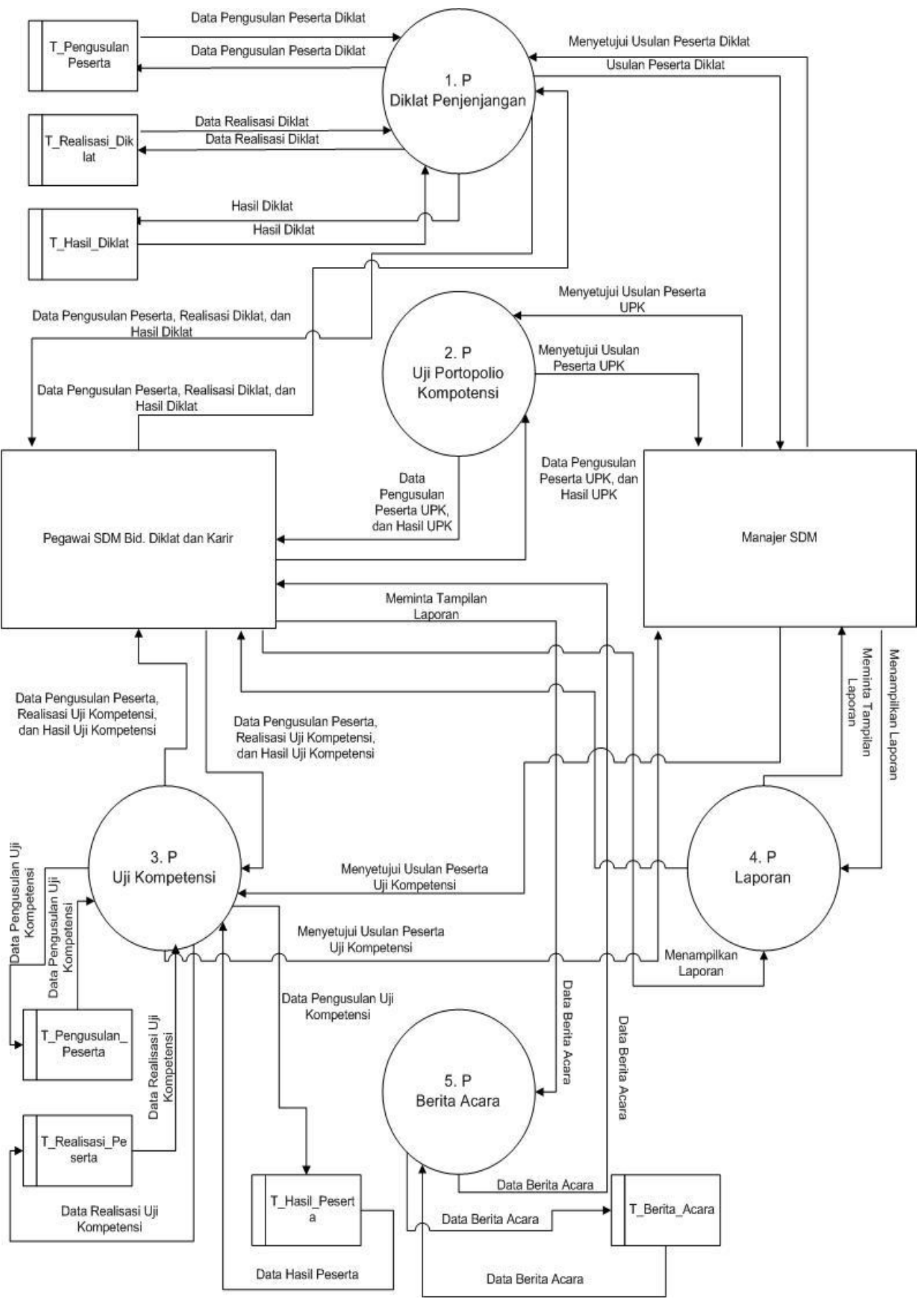




\section{d. Diagram Level 2 Diklat Penjenjangan}

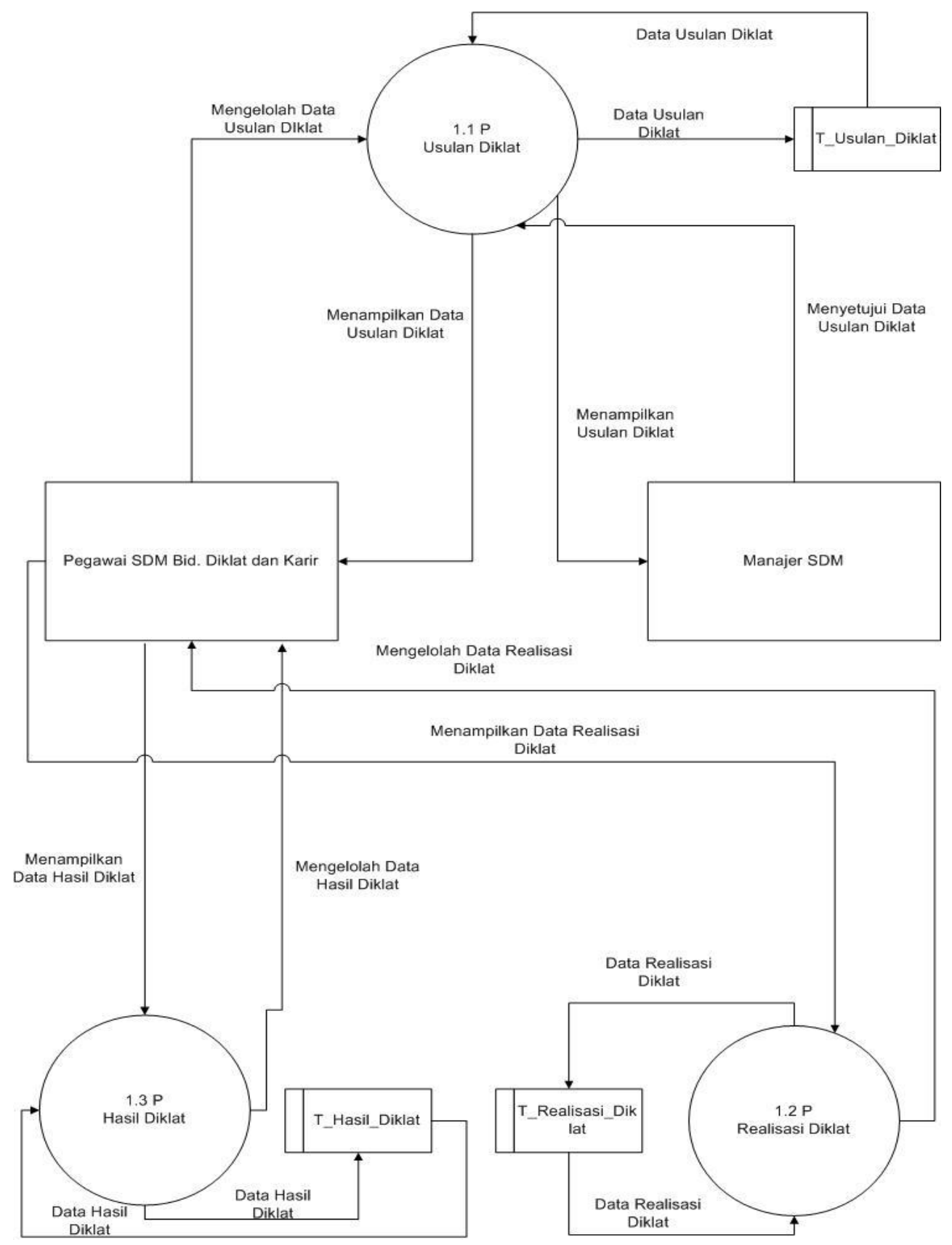


Farida Yusuf, Rancang dan Bangun Sistem Informasi Administrasi Diklat pada PT PLN ..._ 223

\section{e. Diagram Level 2 Uji Kompetensi}

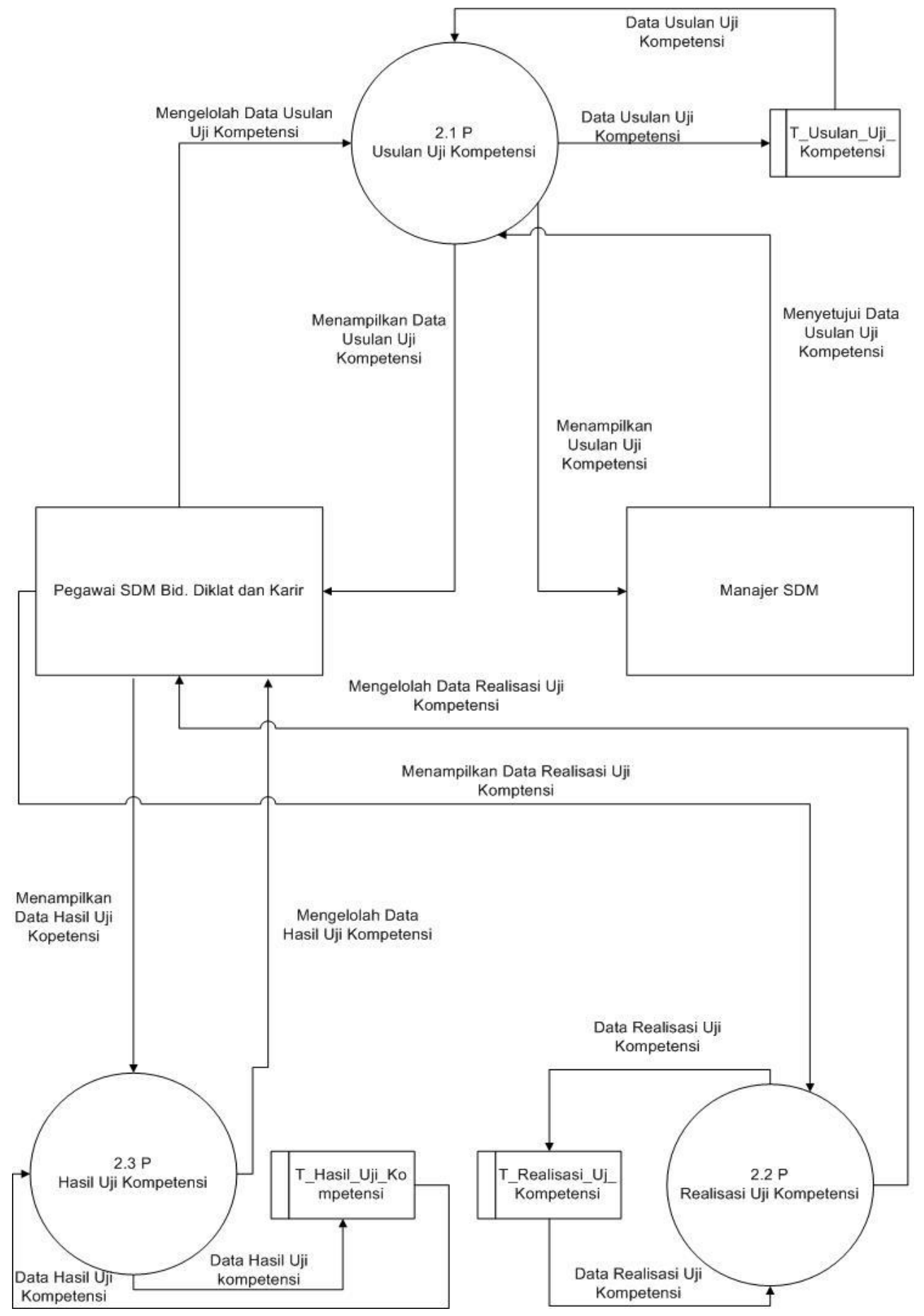




\section{f. Diagram Level 2 Uji Portofolio Kompetensi}

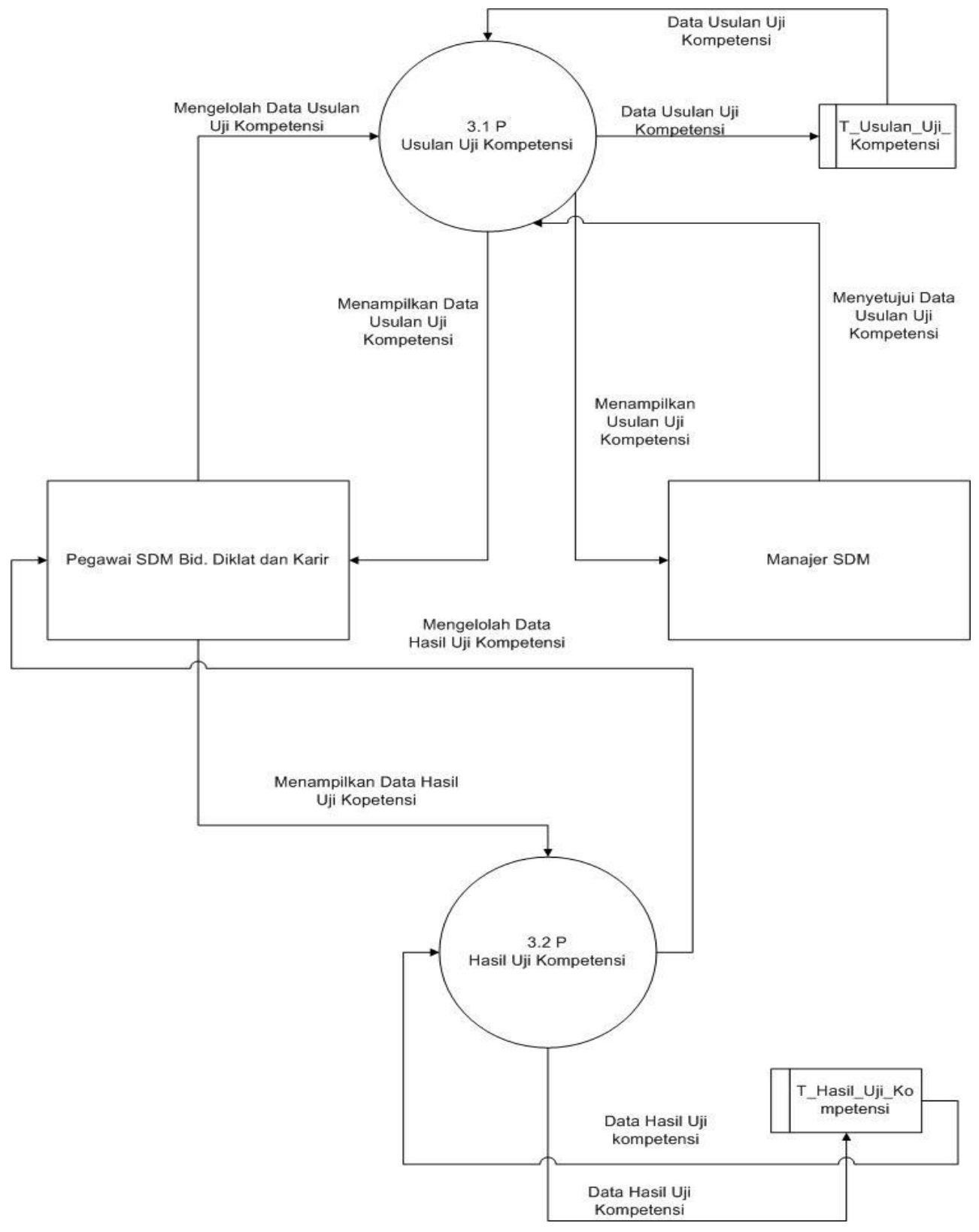




\section{g. Diagram Level 2 Laporan}

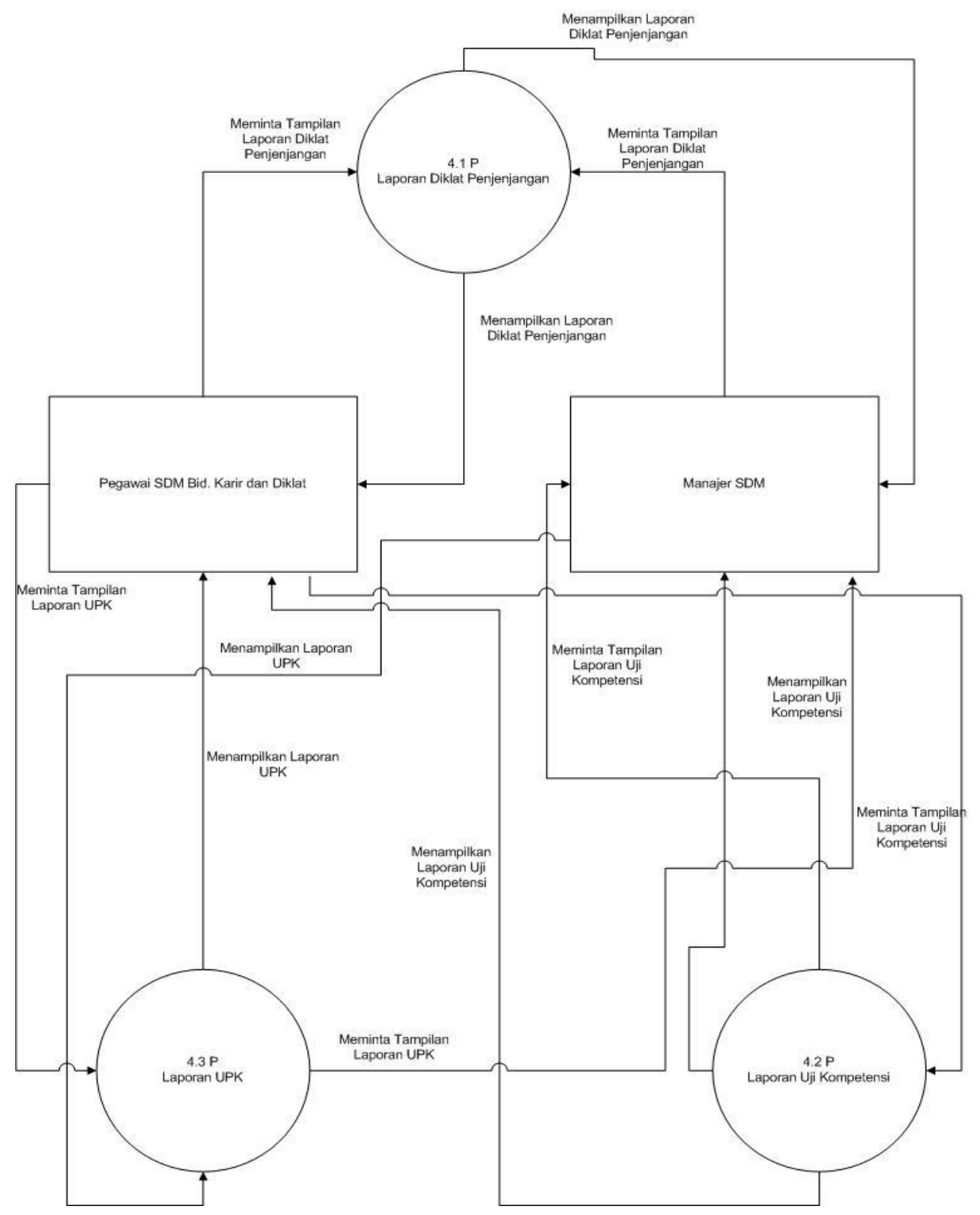

\section{4) Implementasi Aplikasi}

Implementasi merupakan tahap penerapan dan pengujian bagi sistem berdasarkan hasil analisa dan perancangan dari bab IV. Pada bab V ini merupakan implementasi hasil rancangan menjadi sebuah aplikasi Rancang Bangun Sistem Publikasi Realisasi Anggaran Desa Berbasis Web dengan menggunakan database MySQL. 


\section{5) Tampilan Sistem}

1) Halaman login

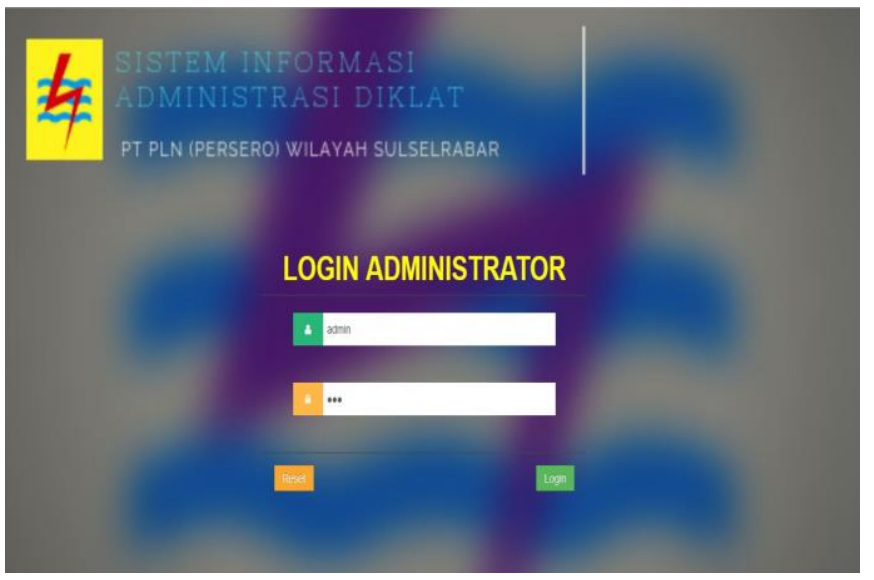

2) Tampilan Halaman Utama

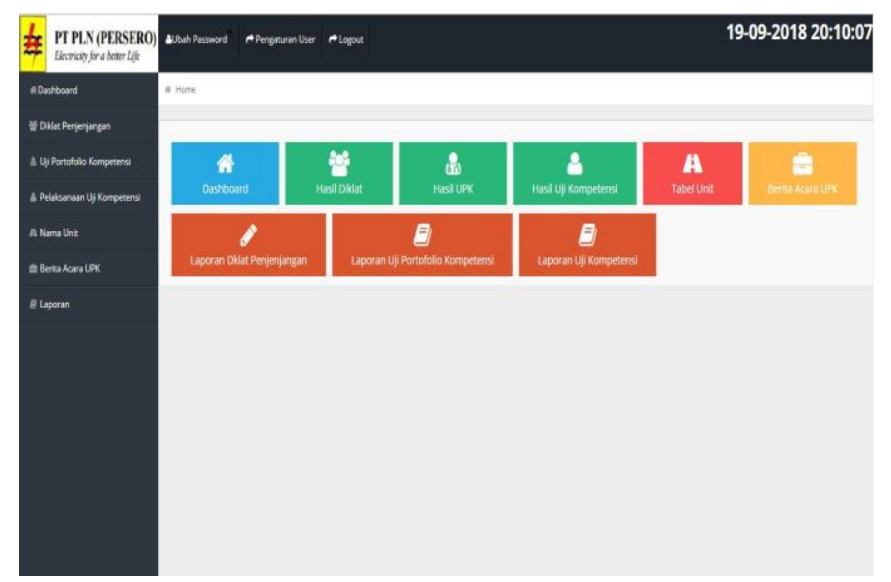

3) Tampilan Laporan

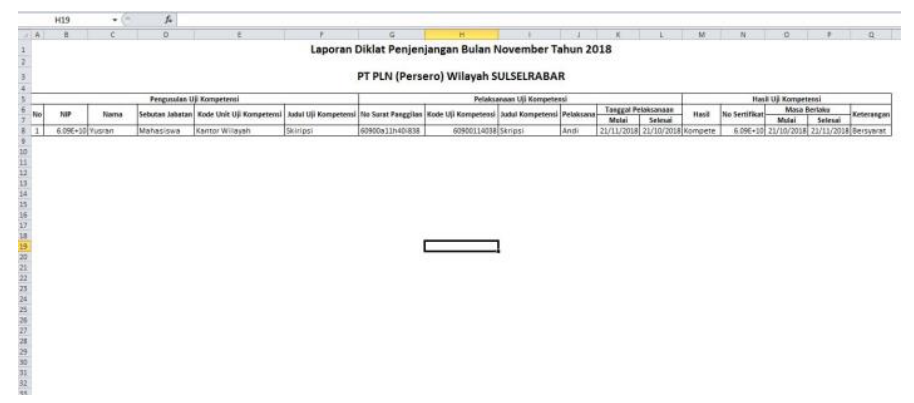




\section{KESIMPULAN}

Berdasarkan hasil analisis sistem informasi administrasi diklat pada PT. PLN (Persero) Wilayah SULSELRABAR, maka dapat mengambil kesimpulan bahwa :

1. Dengan adanya sistem informasi administrasi diklat, ini memenuhi kebutuhan dalam memonitoring diklat di PT PLN (Persero) Wilayah SULSELRABAR.

2. Pengelolahan data dan penyajian informasi menjadi efektif dan efesien.

3. Adanya sistem ini membuat data-data tentang diklat di wilayah Sulawesi Selatan, Tenggara, dan Barat menjadi terintegrasi dan memudahkan pegawai bagian diklat dan manajer SDM dapat memenuhi pekerjaannya dengan cepat dan tepat.

\section{DAFTAR PUSTAKA}

Ardhana, YM Kusuma. 2012. Menyelesaikan Website 30 Juta!. Jakarta: Jasakom. Asropudin, Pipin. 2013. Kamus Teknologi Informasi. Bandung: Titian Ilmu.

Buana, I Komang Setia. 2014. Jago pemrograman PHP. Jakarta: Dunia Komputer.

Dewi, Irra Chrisyanti. 2011. Pengantar Ilmu Administrasi. Jakarta: PT Pustakarya.

Fachri, Fandi Faisyal. 2017. Pengembangan dan Analisis Sistem Informasi Diklat Berbasis Teknologi Informasi Di PPPPTK Seni dan Budaya Yogyakarta. Yogyakarta: Jurnal Pendidikan Pendidikan Teknik Informatika.

Gerhaantara, Rachmat dan Febriliyan Samopa. 2013. Pembuatan Sistem Informasi Pendidikan dan Pelatihan dalam Jabatan Berbasis Web pada Bagian Pengembangan Pegawai Direktorat Jenderal Perbendaharaan. Surabaya : Jurnal Teknik Pomits Vol.2, No.2.

Jogiyanto. 2010. Analisis dan Desain Sistem Informasi Edisi IV. Yogyakarta : Andi Offset.

Ladjamudin, Al Bahran bin. 2008. Rekayasa Perangkat Lunak. Yogyakarta : Penertbit Graha Ilmu. 
Lestari, Indah. 2017. Rancang dan Bangun Sistem Informasi Alih Daya pada PT PLN (Persero) Wilayah SULSELRABAR. Makassar : Skripsi UIN Alauddin Makassar.

Madcoms. 2012. Java Script untuk membangun website professional. Yogyakarta: Penerbit Andi.

Nugroho, Bunafit. 2013. Dasar Pemograman Web PHP-MySQL Dengan Dreamweaver. Yogyakarta: Gava Media.

Pressman, Roger S. 2014. Rekayasa Perangkat Lunak - Buku Satu, Pendekatan Praktisi Edisi 8. Yogyakarta : Andi.

Rosa. A.S., dan Shalahuddin. M. 2014. Rekayasa Perangkat Lunak. Cet. II; Bandung:Informatika.

Subekti, S.H., Prof. R., dan R. Tjitrosudibio. 2013.Kitab Undang-Undang Hukum Perdat. Jakarta : Pradnya Pramita.

Supardi, Yanuar. 2010. Analisis dan Desain Sistem Informasi. Jakarta : PT Gramedia Pustaka Utama.

Universitas Islam Negeri Alauddin Makassar. 2014. PEDOMAN PENULISAN KARYA TULIS ILMIAH: Makalah, Skripsi, Disertasi, dan Laporan Penelitian. Makassar : UIN Alauddin.

Wagimin, dan lain-lain. 2017. Rancang Bangun Sistem Informasi Monitoring Sertifikasi Pegawai Berbasis Web pada PT PLN (Persero) Wilayah Kalimantan Barat. Kalimantan : Jurnal Sistem dan Teknologi Informasi (JUSTIN) Vol. 5, No. 3. 